\title{
Study on anaerobic co-digestion of cow manure, maize straw and vegetable waste
}

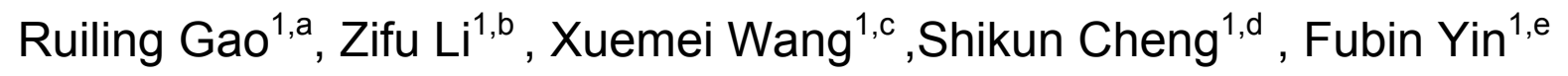 \\ ${ }^{1}$ Department of Environmental Engineering, University of Science and Technology Beijing, China \\ agaoruiling515@126.com, bzifulee@aliyun.com, \\ cwangxuemei0000@126.com, ${ }^{\mathrm{d}}$ chengshikun_1985@aliyun.com, ${ }^{\mathrm{e}}$ carft_257@163.com
}

Keywords: biogas, anaerobic co-digestion, multiple-feedstocks, vegetable waste, acidification.

\begin{abstract}
Anaerobic co-digestion strategies has become the development trend of biogas engineerin g. Most of the lab researches and engineering projects only stay on the two kinds of material mixed fermentation. In order to further solve the problem of raw material shortage and nutritional imbalan ce, multiple-feedstocks anaerobic co-digestion has become a hotspot of research. This study selected cow manure and maize straw anaerobic fermentation system to add vegetable waste as the third mix ed material. Under mesophilic condition $\left(37 \pm 1^{\circ} \mathrm{C}\right)$, a bench-scale experiment based on anaerobic co -digestion process of this multipe-feedstocks mixtures was conducted in a fed-batch single phase rea ctor. The biogas production performance was analyzed under different material mixture ratios as R1 $\sim$ R9. Compared with 12.65 and 4.22, when the TS ratio of cow manure and maize straw was 6.34 (R 4 , R5), the system has the best performance in biogas production. Excess vegetable waste (75 g) led to serious acidification phenomena in R3, R6 and R9, as daily gas production quickly dropped to al most no gas before the 5th day. By adding appropriate amount of $\mathrm{NaOH}$ solution to adjust $\mathrm{pH}$ to 7.5 0 , through $10 \sim 15$ days of recovery, methane bacteria activity gradually restored and therewith the gas production rate increase. In terms of gas production performance, $\mathrm{R} 4>\mathrm{R} 5>\mathrm{R} 2>\mathrm{R} 1>\mathrm{R} 7>\mathrm{R} 8$. $\mathrm{R} 4$ had the highest biogas production with $8870 \mathrm{~mL}$ cumulative biogas production, $311.12 \mathrm{~mL} \cdot \mathrm{g}^{-1}$ TS biogas yield of feedstock and $66.1 \%$ methane percentage.
\end{abstract}

\section{Introduction}

With the development of economy and the improvement of people's living standard, the output of urban living garbage, which the vegetable waste occupies a large proportion, is growing. In China, main disposal methods of MSW are landfill, compost and incineration[1]. Due to the high moisture content, vegetable waste is not suitable for incineration, and landfill can produce plenty of leachate that is hard to control and can lead to environmental pollution. Composting needs a large amount of energy consumption of aeration and it is hard to get high quality compost. Anaerobic digestion can not only solve the problem of environmental pollution, but also provide clean renewable energy biogas, so as to realize the recycling of the waste[2]. However, single vegetable waste as raw material can be nutritional imbalance, easily lead to acidification. The VFA accumulation in anaerobic digestion system can cause the drop of $\mathrm{pH}$ value and restrain the methanogens physiological activity, which results in the decrease of gas properties, even the failure of the anaerobic digestion[16].

Anaerobic co-digestion strategies has become the development trend of biogas engineering $[3,4]$. However, most of the lab research and engineering project only stay on the two kinds of material mixed fermentation [5 7]. Therefore, this study selected cow manure and maize straw anaerobic digestion system to add vegetable waste as the third mixed material. Under mesophilic condition $\left(37 \pm 1^{\circ} \mathrm{C}\right)$, a bench-scale experiment based on anaerobic co-digestion process of this ternary mixtures was conducted in a fed-batch single phase reactors. The biogas production performance and the reasonable material ratio was analyzed in order to provide the basis of the design and operation of anaerobic co-digestion process with cow manure, maize straw and vegetable waste. 


\section{Material and Method}

2.1 Material. In this study, ternary mixtures with Cow Manure (CM), Maize Straw (MS) and Vegetable Waste (VW) were tested. Cow manure was collected from a dairy farm, Jinyindao, in Beijing, China and inoculum was obtained from a mesophilic digester on this farm. Maize straw from Beijing suburban farmland was chopped to a particle size of approximately $2 \mathrm{~mm}$. Vegetable waste was collected, during September 2014, form a vegetable market. It was mixed and chopped to a particle size of approximately $5 \mathrm{~mm}$. The characteristics of the substrates and inoculum tested in this study are shown in Table 1.

Table 1. The characteristics of the substrates and inoculum

\begin{tabular}{ccccc}
\hline & Cow manure & Maize straw & Vegetable waste & Inoculum \\
\hline TS [\%ww] & 23.40 & 92.27 & 5.66 & 5.40 \\
VS [\%ww] & 20.59 & 83.04 & 4.73 & 2.97 \\
VS/TS & 0.88 & 0.90 & 0.84 & 0.55 \\
Total C [\%] & 33.80 & 41.76 & 38.62 & 15.56 \\
Total N [\%] & 1.96 & 1.36 & 2.87 & 1.70 \\
C/N & 17.24 & 30.68 & 13.46 & 9.15 \\
\hline
\end{tabular}

2.2 Experiment set-up. The batch test set-up as shown in Fig. 1 consists of 1L jars as digesters and $1 \mathrm{~L}$ graduated cylinders as biogas collectors. The digesters were kept in the thermostat water bath at a constant temperature of $37 \pm 1{ }^{\circ} \mathrm{C}$ in order to maintain constant reaction temperature. A gas-tight rubber pipe transported the biogas generated in the digesters to the graduated cylinders. By this action, the water was pressed out of the graduated cylinders into the water tank. The volume of the headspace of the graduated cylinders represents the volume of the biogas generated in the digesters.

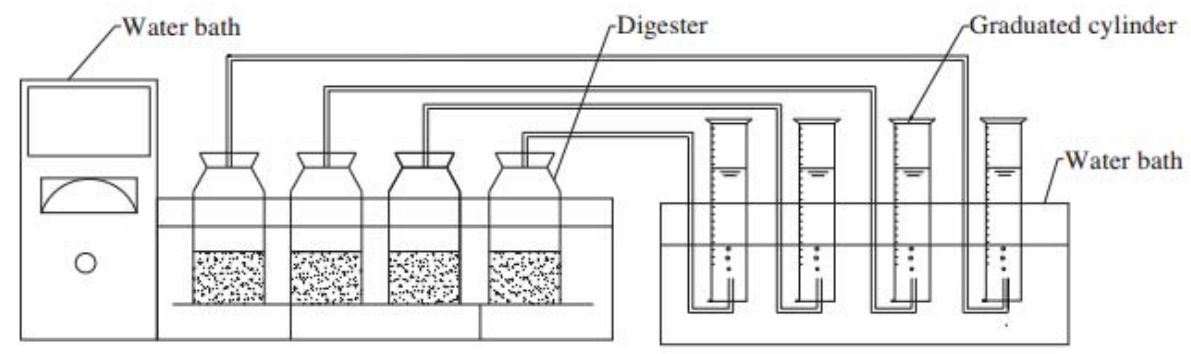

Fig. 1. Experiment set-up

2.3 Method. In this co-digestion experiment, the weight ratio of cow manure and maize straw were studied at three level, 50:1, 50:2 and 50:3 (corresponding TS ratio were 12.65, 6.34 and 4.22) expressed as R1 R3, R4 R6 and R7 R9 respectively. Different amount (25g, 50g, 75g) of vegetable waste was added as the third kind of mixed material. $150 \mathrm{ml}$ of inoculum was added to each digester (inoculation volume fraction was 30\%). Mixed material in each digester was diluted with deionized water to $500 \mathrm{ml}$ after inoculation. Moreover, a blank test was added to the experiment using only a substrate of the inoculum. The composition and calculated TS of cow manure, maize straw, vegetable waste and inoculum were shown in Table 2 and Table 3.

The biogas generated was collected through a gas-tight tube inserted into the digester headspace, which, by water displacement, allows the generated biogas to flow into the graduated cylinder. For each test, the volume of the gas produced and the concentration of methane determined by a Biogas Analyzer were measured daily. Once every 3 days, samplings from the digesters were taken, and the pH were measured accordingly. 
Table 2. Composition of cow manure, maize straw, vegetable waste and inoculum

\begin{tabular}{cccccc}
\hline & $\begin{array}{c}\text { Weight ratio of } \\
\text { CM : MS }\end{array}$ & $\begin{array}{c}\text { Cow manure } \\
{[\mathrm{g}]}\end{array}$ & $\begin{array}{c}\text { Maize straw } \\
{[\mathrm{g}]}\end{array}$ & $\begin{array}{c}\text { Vegetable waste } \\
{[\mathrm{g}]}\end{array}$ & $\begin{array}{c}\text { Inoculum } \\
{[\mathrm{mL}]}\end{array}$ \\
\hline & & 100 & 2 & 25 & 150 \\
\hline R1 & \multirow{2}{*}{$50: 1$} & 100 & 2 & 50 & 150 \\
R2 & & 100 & 2 & 75 & 150 \\
R3 & \multirow{2}{*}{$50: 2$} & 100 & 4 & 25 & 150 \\
\hline R4 & 100 & 4 & 50 & 150 \\
R5 & & 100 & 4 & 75 & 150 \\
R6 & \multirow{2}{*}{$50: 3$} & 100 & 6 & 25 & 150 \\
\hline R7 & & 100 & 6 & 50 & 150 \\
R8 & & 100 & 6 & 75 & 150 \\
R9 & & - & - & - & 150 \\
\hline Blank & - & & &
\end{tabular}

Table 3. Calculated TS of cow manure, maize straw, vegetable waste and inoculum

\begin{tabular}{|c|c|c|c|c|c|c|}
\hline & $\begin{array}{l}\text { TS ratio of } \\
\text { CM : MS }\end{array}$ & $\begin{array}{c}\text { Cow manure } \\
{[\mathrm{gTS}]}\end{array}$ & $\begin{array}{c}\text { Maize straw } \\
\text { [gTS] }\end{array}$ & $\begin{array}{c}\text { Vegetable waste } \\
\text { [gTS] }\end{array}$ & $\begin{array}{l}\text { Inoculum } \\
\text { [gTS] }\end{array}$ & $\begin{array}{c}\mathrm{TS} \\
{[\% \mathrm{ww}]}\end{array}$ \\
\hline R1 & \multirow{3}{*}{12.65} & 23.40 & 1.85 & 1.42 & 8.10 & 6.95 \\
\hline R2 & & 23.40 & 1.85 & 2.83 & 8.10 & 7.24 \\
\hline R3 & & 23.40 & 1.85 & 4.25 & 8.10 & 7.52 \\
\hline R4 & \multirow{3}{*}{6.34} & 23.40 & 3.69 & 1.42 & 8.10 & 7.32 \\
\hline R5 & & 23.40 & 3.69 & 2.83 & 8.10 & 7.60 \\
\hline R6 & & 23.40 & 3.69 & 4.25 & 8.10 & 7.89 \\
\hline R7 & \multirow{3}{*}{4.22} & 23.40 & 5.54 & 1.42 & 8.10 & 7.69 \\
\hline R8 & & 23.40 & 5.54 & 2.83 & 8.10 & 7.97 \\
\hline R9 & & 23.40 & 5.54 & 4.25 & 8.10 & 8.26 \\
\hline
\end{tabular}

\section{Results and discussion}

3.1 Biogas production performance. The biogas production performance of $R 1 \sim R 9$ are shown in Table 4. All the test with $75 \mathrm{~g}$ weight of vegetable waste, that is R3, R6, R9, appeared serious acidification phenomena. The gas production quickly dropped to almost no gas before the 5th day (Fig. 5).

The daily biogas production and cumulative biogas volume of R1, R2, R4, R5, R7, R8 throughout the entire process of digestion were respectively shown in Figs. 2 and Figs. 3. Considered the cumulative gas volume of the blank test is $1285 \mathrm{~mL}$, the values of the cumulative gas volume in the mixed substrates of R1, R2, R4, R5, R7, R8 were respectively $6515,7050,8870,8105,5555$ and $4145 \mathrm{~mL}$. The biogas yeild of feedstock were 244.37, 251.07, 311.12, 270.89, 183.03 and 130.47 $\mathrm{ml} \cdot \mathrm{g}^{-1} \mathrm{TS}$.

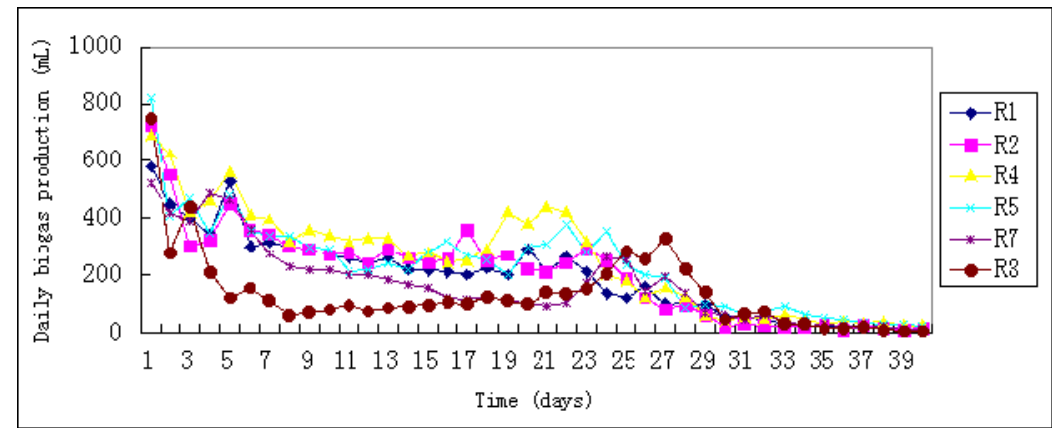

Fig. 2. Daily biogas production of R1,R2,R4,R5,R7,R8 with digestion time 


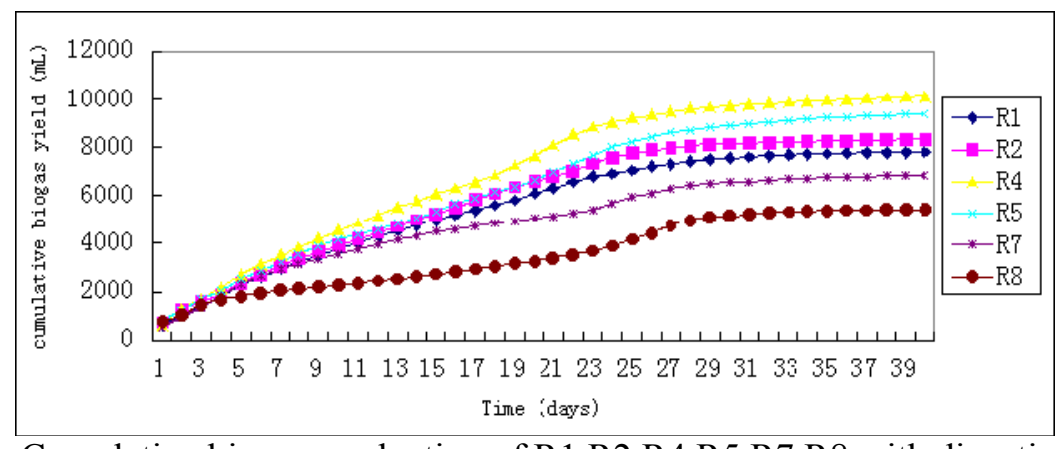

Fig. 3. Cumulative biogas production of $\mathrm{R} 1, \mathrm{R} 2, \mathrm{R} 4, \mathrm{R} 5, \mathrm{R} 7, \mathrm{R} 8$ with digestion time

According to Fig.2, the daily gas production of each test all reached the first peak on the 1st day. At this time, the composition of the produced gas were mainly hydrogen and carbon dioxide. Soon afterwards, a certain degree of acidification phenomena appeared on the 2 nd day and restrained the activities of anaerobic bacteria, greatly reduced the gas production. R1, R2, R4, R5, R7 had a fast recovery of gas production during the $3 \mathrm{rd} \sim 5$ th days and reached a second peak during the 15 th $\sim$ 25 th days. Gas component content was stable at this phase and the highest methane percentage of R1, R2, R4, R5, R7 was $62.9 \%, 62.3 \%, 66.1 \%, 65.5 \%, 59.2 \%$ respectively. The inhibiting effect of acidification on gas production lasted in R8, but through a long time (about 12 days) of the adjustment of the system itself, gas production slowly recovered. Nevertheless, the gas production rate of R8 was still at a very low level compared with R1, R2, R4, R5, R7. The cumulative gas volume was $4145 \mathrm{ml}$ and the biogas yeild of feedstock was merely $130.47 \mathrm{ml} \cdot \mathrm{g}^{-1} \mathrm{TS}$. The methane percentage fluctuated within the range of $29.0 \% \sim 34.8 \%$.

The results above showed that compared with 12.65 and 4.22, when the TS ratio of cow manure and maize straw was 6.34 (R4, R5), the system has the best performance in gas production. Analyzed reason was that adding suitable amount of maize straw helped to optimize the $\mathrm{C} / \mathrm{N}$ of the system, while too much maize straw was not conducive to biogas digestion as maize straw contained lots of substances that is difficult to decompose, such as cellulose and lignin [8 10]. Therefore, the gas production performance in R7 and R8 were not ideal. The proportion of more vegetable waste produced more VFA, which can be used by methanogens as nutrition medium. But the accumulation of too much VFA can lead to excessive acidity and inhibit the activity of methanogens. All the test with $75 \mathrm{~g}$ weight of vegetable waste, that is R3, R6, R9, appeared serious acidification phenomena. Among R1 R9, R4 with a appropriate blending ratio of cow manure, maize straw and vegetable waste had a best biogas production performance.

Table 4. The biogas production performance of R1 R9

\begin{tabular}{cccccc}
\hline & $\begin{array}{c}\text { Cumulative } \\
\text { biogas yeild of } \\
\text { reactor [mL] }\end{array}$ & $\begin{array}{c}\text { Cumulative } \\
\text { biogas yeild of } \\
\text { feedstock }[\mathrm{mL}]\end{array}$ & $\begin{array}{c}\text { Biogas yeild of } \\
\text { of reactor } \\
{[\mathrm{mL} / \mathrm{gTS}]}\end{array}$ & $\begin{array}{c}\text { Biogas yeild of } \\
\text { feedstock } \\
{[\mathrm{mL} / \mathrm{gTS}]}\end{array}$ & $\begin{array}{c}\text { Methane } \\
\text { percentage } \\
{[\%]}\end{array}$ \\
\cline { 2 - 6 } R1 & 7800 & 6515 & 224.40 & 244.37 & 62.9 \\
R2 & 8335 & 7050 & 230.38 & 62.3 \\
R3 & \multicolumn{5}{c}{ Acidification } \\
\hline R4 & 10155 & 8870 & 277.38 & 66.1 \\
R5 & 9390 & 8105 & 246.98 \\
R6 & \multicolumn{5}{c}{ Acidification } \\
\cline { 2 - 6 } R7 & 6840 & 5555 & 270.89 & 65.5 \\
R8 & 5430 & 5145 & 177.89 \\
R9 & \multicolumn{5}{c}{136.19} \\
\hline
\end{tabular}

The cumulative biogas production of Blank test was $1285 \mathrm{ml}$.

3.2 $\mathrm{pH}$ value and acidification. The $\mathrm{pH}$ plays an important role in the growth of microbes during anaerobic digestion. It should be kept within neutral range because of the sensitivity of microorganisms $[11,13]$. Digestion process can be in fact inhibited by excessive acidity. 
The $\mathrm{pH}$ values of each test throughout the entire process of digestion were shown in Fig. 4. The initial $\mathrm{pH}$ values of $\mathrm{R} 1 \sim \mathrm{R} 9$ were all around 7.2. With the anaerobic digestion process, $\mathrm{pH}$ value gradually reduced during the first few days because of the VFA accumulation form the hydrolysis acidification phase $[15,16]$. Among them, R1, R2, R4, R5, R7 reduced to their lowest $\mathrm{pH}$ value within the range of $6.3 \sim 6.6$ on the 5 th or 6 th day, then rise slowly and finally maintained at a stable level ranging $6.8 \sim 7.0$. This means that there were no excessive acidity restraining the survival of anaerobic bacteria in R1, R2, R4, R5, R7. When methanogenic bacteria began to degrade VFA effectively and $\mathrm{NH}_{4}-\mathrm{N}$ from the ammoniation phase during medium-term digestion played a buffer role, the $\mathrm{pH}$ values gradually increased $[13,14]$.

A certain degree of acidification affected the recovery of $\mathrm{pH}$ value and gas production in $\mathrm{R} 8$. On the 5th day, the $\mathrm{pH}$ of $\mathrm{R} 8$ was 6.17 and continued to fall to the low value 5.99 (9th day), then the $\mathrm{pH}$ rise very slowly to 6.88 (25th day) and gradually dropped to 6.57 . Meanwhile, the gas production rate kept at a very low level compared with R1, R2, R4, R5, R7 (Fig.2, Fig.3).

The results above showed that the proportion of more vegetable waste $(50 \mathrm{~g})$ produced more VFA, while too much maize straw proportion further affected the digestive process, which reduces system itself to regain the $\mathrm{pH}$ buffer [10]. Yet, it could not be acidified critically and no additional material was needed to adjust the $\mathrm{pH}$.

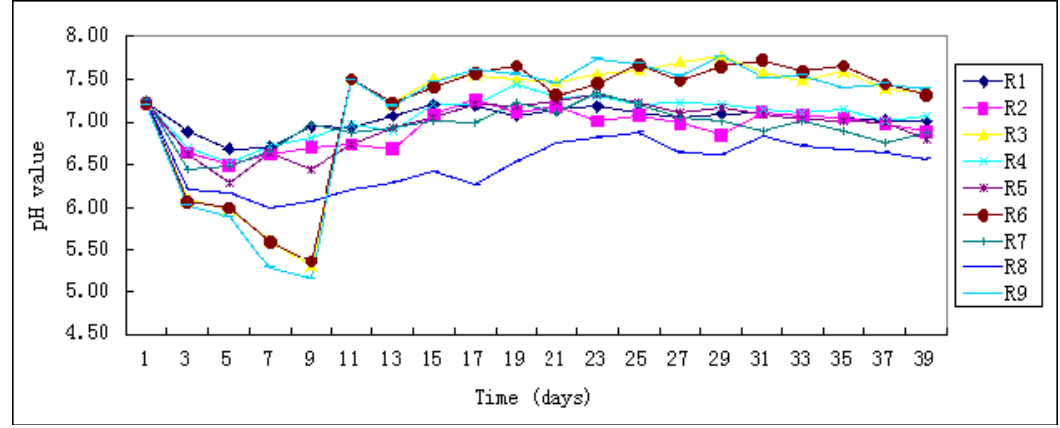

adjust the pH of R3,R6,R9 to 7.50 with $\mathrm{NaOH}$ solution on the 10th day

Fig. 4. $\mathrm{pH}$ with digestion time

Excess vegetable waste ( $75 \mathrm{~g})$ led to serious acidification phenomena appeared in R3, R6 and R9. The gas production quickly dropped to almost no gas before the 5th day (Fig. 5). On the 10th day measured the $\mathrm{pH}$ of $\mathrm{R} 3, \mathrm{R} 6$ and $\mathrm{R} 9$ was 5.30, 5.36 and 5.15 respectively. Under this condition, methanogens growth are severely restrained. By adding appropriate amount of $\mathrm{NaOH}$ solution to adjust $\mathrm{pH}$ to 7.50 (on the 10th day), through $10 \sim 15$ days of recovery, methanogens activity gradually restored and therewith the gas production rate increased. The largest daily gas production of R3, R6 and $\mathrm{R} 9$ after $\mathrm{pH}$ adjustment was $365 \mathrm{ml}, 440 \mathrm{ml}, 460 \mathrm{ml}$ respectively. The variation of $\mathrm{pH}$ and gas production were shown in Fig. 4 and Fig. 5.

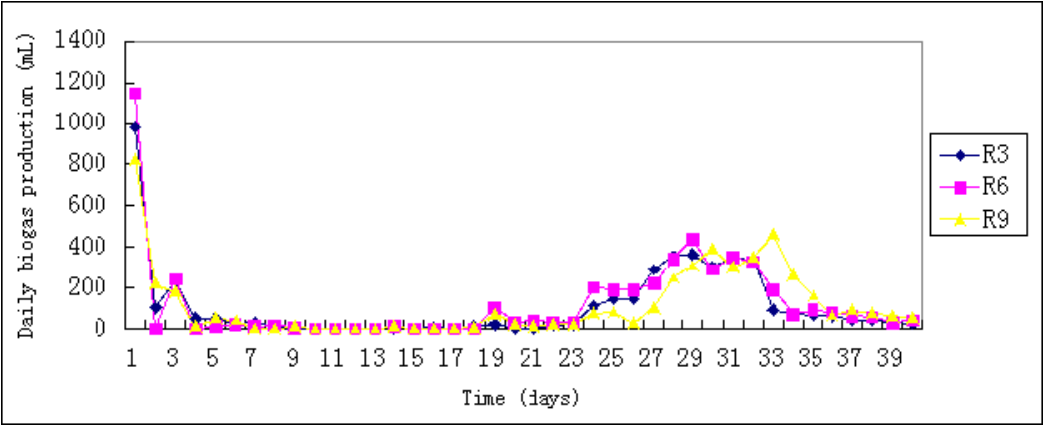

Fig. 5. Daily biogas production of R3, R6, R9 before and after $\mathrm{pH}$ adjustment

\section{Conclusions}

Compared with 12.65 and 4.22, when the TS ratio of cow manure and maize straw was 6.34 (R4, $\mathrm{R} 5$ ), the system has the best performance in gas production. Analyzed reason was that adding suitable amount of maize straw helped to optimize the $\mathrm{C} / \mathrm{N}$ of the system, while too much maize straw was not 
conducive to biogas digestion as maize straw contained lots of substances that is difficult to decompose, such as cellulose and lignin.

The proportion of more vegetable waste produced more VFA, which can be used by methanogens as nutrition medium. But the accumulation of too much VFA can lead to excessive acidity and inhibit the activity of methanogens. All the test with $75 \mathrm{~g}$ weight of vegetable waste, that is R3, R6, R9, appeared serious acidification phenomena. The gas production quickly dropped to almost no gas before the 5th day (Fig. 5). By adding appropriate amount of $\mathrm{NaOH}$ solution to adjust $\mathrm{pH}$ to 7.50, through $10 \sim 15$ days of recovery, methane bacteria activity gradually restored and therewith the gas production rate increase.

The cumulative biogas production volume in the mixed substrates of R1, R2, R4, R5, R7, R8 were respectively $6515,7050,8870,8105,5555$ and $4145 \mathrm{~mL}$. The biogas yeild of feedstock were 244.37 , 251.07, 311.12, 270.89, 183.03 and $130.47 \mathrm{ml}^{-1} \mathrm{TS}$. Among R1 R9, R4 with a appropriate blending ratio of cow manure, maize straw and vegetable waste had a best biogas production performance.

\section{Acknowledgements}

This study was supported by grants from the projects of D141100001214003 and 2013DFG92620. The authors wish to thank the Beijing Sanyi Green Energy Development Co., Ltd and the Sanyuan treasure island dairy farm.

\section{References}

[1] Ning Pin. Solid waste treatment and disposal [M]. Beijing, Higher Education Press. (2007)

[2] Y.L. Fu, J. R. Qiu, et al. Research progress on anaerobic digestion of fruit and vegetable wastes. Guangdong Agricultural Science 20 (2013), p. 185-187

[3] E. Marañ ó n, L. Castrill ó n, G. Quiroga, Y. Fern á ndez-Nava, L. G ó mez, M.M. Garc í a.Co-digestion of cattle manure with food waste and sludge to increase biogas production. Waste Management 32 (2012), p.1821-1825

[4] B. Amon, T.Amon, V.Kryvoruchko, K.M.Zollitsch, L.Gruber. Biogas production from maize and dairy cattle manure: influence of biomass composition on the methane yield. Agric. Ecosyst. Environ. 118 (2007), p.173-182.

[5] Elena Comino, A.Vincenzo, Riggio, Maurizio Rosso. Biogas production by anaerobic co-digestion of cattle slurry and cheese whey. Bioresource Technology 114 (2012), p.46-53

[6] Hamed M. El-Mashad, Ruihong Zhang. Biogas production from co-digestion of dairy manure and food waste. Bioresource Technology 101 (2010), p.4021-4028

[7] Xiao Wu, Wanying Yao, Jun Zhu, Curtis Miller. Biogas and CH4productivity by co-digesting swine manure with three crop residues as an external carbon source. Bioresource Technology 101 (2010), p. 4042-4047

[8] S.Schwede, A.Kowalczyk, M.Gerber, eta1.Anaerobic co-digestion of the marine microalga Nannochloropsis salina with energy crops. Bioresource Technology, 148 (2013), p.428-435.

[9] K. Butkowska, T. Pokój, E. Klimiuk, et a1. Optimization of anaerobic digestion of a mixture of Zea mays and Miscanthus sacchariflorus silages with various pig manure dosages. Bioresource Technology, 125(2012), p. 208-216.

[10] Dejing Liu.Experiment on biogas fermentation with different proportion of corn straw mixed with cow dung. China Biogas, 27(2009), p. 13-18 
[11] Fubin Yin, Dongling Wang, Zifu Li, Thomas Ohlsen, Peter Hartwig, Sven Czekalla.Study on anaerobic digestion treatment of hazardous colistin sulphate contained pharmaceutical sludge. Bioresource Technology 177 (2015), p. 188-193

[12] A.J.Ward, P.J.Hobbs, P.J.Holliman, D.L.Jones. Optimisation of the anaerobic digestion of agricultural resources. Bioresour. Technol.99 (2008), p. 7928-7940

[13] T.R.Sreektishnan, S.Kohli, V.Rana. Enhancement of biogas production from solid substrates using different techniques-a review. Bioresource technology, 95(2004), p. 1-10.

[14] Uludag-Demirer,G.N. Demirer, Frear, et al. Anaerobic digestion of dairy manure with enhanced ammonia removal. Environ Manage, 86(2008), p.193-200.

[15] Rada EC, Ragazzi M, Torretta V. Laboratory-scale anaerobic sequencing batch reactor for treatment of stillage from fruit distillation. Water Sci Technol, 67(2013),p.1068-1074.

[16] H. Bouallagui, H. Lahdheb, eta1. Improvement of fruit and vegetable waste anaerobic digestion performance and stability with co-substrates addition. Environ Manage. 90(2009), p.1844-1849. 